\title{
Nephrotic Syndrome with Lesion of Membranous Glomerulonephritis
}

National Cancer Institute

\section{Source}

National Cancer Institute. Nephrotic Syndrome with Lesion of Membranous

Glomerulonephritis. NCI Thesaurus. Code C35215.

A renal functional disorder characterized by proteinuria, edema, hyperlipidemia and hypoalbuminemia. It results from damage to the renal vascular filtration apparatus. It is further characterized by an inflammatory reaction in the glomerular capillaries due to the deposition of immune complexes and subsequent thickening of the glomerular basement membrane. Sequelae may include hypertension, atherosclerosis, infection, hypercoagulablity and renal failure. 